\title{
A 2.4-GHz Low-Power/Low-Voltage Wireless Plug-and-Play Module for EEG Applications
}

João Paulo Carmo, Student Member, IEEE, Nuno Sérgio Dias, Student Member, IEEE, Helder Raul Silva, Paulo Mateus Mendes, Member, IEEE, Carlos Couto, Senior Member, IEEE, and José Higino Correia, Member, IEEE

\begin{abstract}
This paper presents a plug-and-play module for wireless electroencephalogram (EEG) applications. The wireless module is composed by an electrode, processing electronics, a radio-frequency $(R F)$ transceiver, and an associated antenna. The RF transceiver was fabricated in the UMC RF $0.18 \mu \mathrm{m}$ CMOS process, and operates in the 2.4-GHz ISM band. The receiver has a sensitivity of $-60 \mathrm{dBm}$ and a power consumption of $6.3 \mathrm{~mW}$ from a $1.8 \mathrm{~V}$ supply. The transmitter delivers an output power of $0 \mathrm{dBm}$ with a power consumption of $11.2 \mathrm{~mW}$, for a range of $10 \mathrm{~m}$. It is also presented the electrical performance and comparison between different electrodes for EEG applications, namely sputtered titanium nitride (TiN) electrodes, standard sintered silver/silver chloride $(\mathrm{Ag} / \mathrm{AgCl})$ ring electrodes and sputtered iridium oxide $\left(\mathrm{IrO}_{2}\right)$ electrodes. The experimental results show a better performance of the sputtered $\mathrm{IrO}_{2}$ electrodes compared with the standard sintered $\mathrm{Ag} / \mathrm{AgCl}$ ring electrodes. These results promise a new opportunity for the application of a dry $\mathrm{IrO}_{2}$ electrodes in wireless modules for using in a wearable EEG braincap. These wireless EEG modules will allow patients to wear a brain cap and maintain their mobility, while simultaneously having their electrical brain activity monitored.
\end{abstract}

Index Terms-Plug-and-play module, radio frequency (RF) CMOS transceiver, wireless electroencephalogram (EEG), wireless sensors networks.

\section{INTRODUCTION}

W IRELESS monitoring of human-body signals, ranging from physiological to kinetic information, is an emerging field. Body area network (BAN) is one technology being used, which comprises smart sensors able to communicate wirelessly to a base station. A wireless electroencephalogram (EEG) will provide a breakthrough in the monitoring, diagnostics, and treatment of patients with neural diseases, as epilepsy [1]. A wireless EEG module composed by the neural electrodes (noninvasive and distributed in a braincap), processing electronics and a radio-frequency (RF) transceiver with an associated antenna, will be an important breakthrough in EEG diagnostic (see Fig. 1).

The RF transceiver (attached to an antenna) makes possible the data communication between the braincap and the external monitoring instrumentation used by health professionals. The RF transceiver must have low-power consumption, and small-

Manuscript received January 14, 2007; revised July 9, 2007; accepted July 18, 2007. The associate editor coordinating the review of this paper and approving it for publication was Prof. Okyay Kaynak.

J. P. Carmo is with the Polytechnic Institute of Bragança, 5301-854 Bragança, Portugal (e-mail: jcarmo@ipb.pt).

N. S. Dias, H. R. Silva, P. M. Mendes, C. Couto, and J. H. Correia are with the Department of Industrial Electronics, University of Minho, 4800-058 Guimarães, Portugal.

Digital Object Identifier 10.1109/JSEN.2007.908238

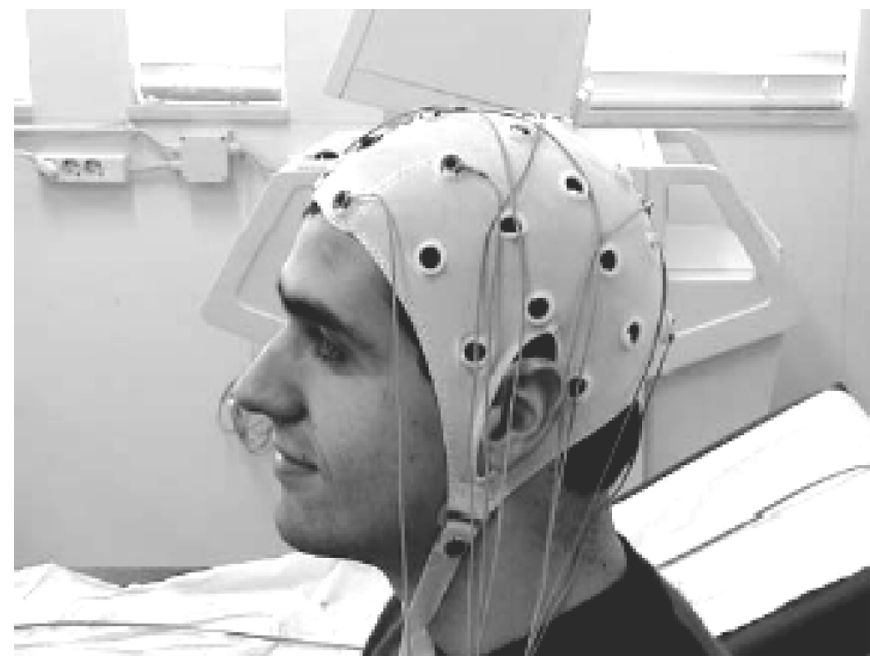

Fig. 1. Classic EEG braincap with $\mathrm{Ag} / \mathrm{AgCl}$ electrodes and respective wires.

size so it can be assembled with an antenna and the EEG electrode. A coin-sized battery placed in the braincap powers the modules. The size-reduction achieved with these modules, make them suitable to be easily plugged and unplugged in the wireless EEG braincap according the medical doctors requirements.

\section{RF CMOS TRANSCEIVER DESIGN}

The UMC RF $0.18 \mu \mathrm{m}$ CMOS process was used for the fabrication of a $2.4-\mathrm{GHz} \mathrm{RF}$ transceiver. This process has a poly layer and six metal layers, allowing integrated spiral inductors (with a reasonable quality factor), high resistor values (a special layer is available), and a low-power supply of $1.8 \mathrm{~V}$. Therefore, a high on-chip integration is possible, in favor of better repeatability, as well as less pin count [2].

The transceiver consists of a receiver, a transmitter, and a frequency synthesizer. The receiver uses direct demodulation by means of envelope detection. It is enough to achieve a bit-error probability less that $10^{-6}$ with a sensitivity of $-60 \mathrm{dBm}$, with a transmitted power of $0 \mathrm{dBm}$ using ASK modulation.

\section{A. Receiver}

Fig. 2 shows the receiver's front-end schematic. The lownoise amplifier (LNA) is the first gain stage in the receiver path where the signal must be amplified as much as possible, with small signal-to-noise ratio (SNR) degradation. This is achieved with the smallest noise figure (NF).

The LNA is an inductively degenerated common source amplifier [3]. This allows the input impedance at $2.4 \mathrm{GHz}$ to be tuned to $50 \Omega$, for matching with antenna. Cascading transistor $\mathrm{M}_{2}$ is used to increase the gain, to better isolate the output 


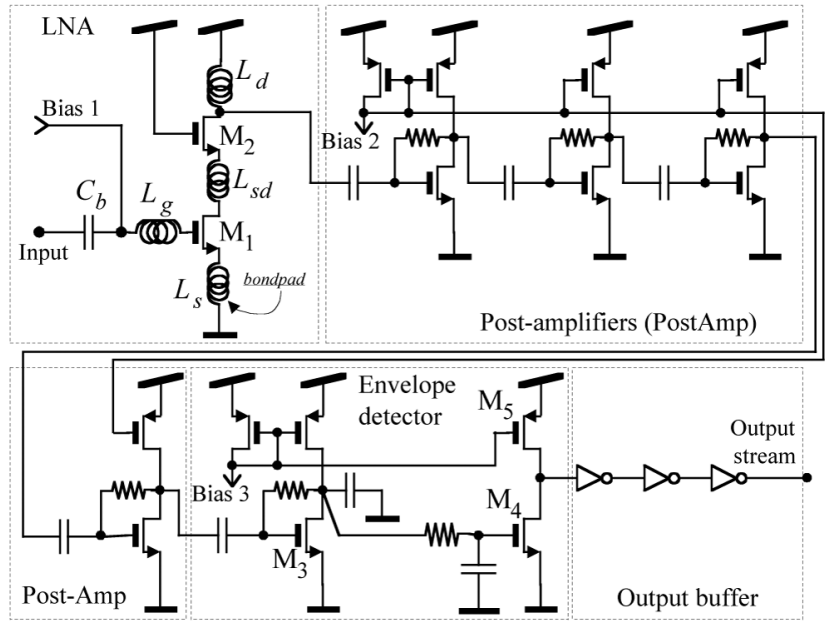

Fig. 2. The schematics of the receiver.

from input and to reduce the effect of $\mathrm{M}_{1}$ 's $C_{g s}$. The LNA may be switched to sleeping mode, by operation of the polarization stages. The same principle applies to the all subsystems of the transceiver. The inductance $L_{\mathrm{s}}$ is implemented with the bonding connection to the external PCB, which has been calculated to be $0.9 \mathrm{nH} / \mathrm{mm}$ [4]. The wires used to connect the die to an external PCB, with a RF substrate, have an inductance that adds to the LNA circuit. The use of the inductance $L_{s d}$, helps to reduce these effects.

A minimum RF level at the envelope detector is achieved by means of further amplification of the signal at the LNA output. This minimum level defines the receiver's sensitivity. The main idea of an envelope detector is as follows: an increasing of the voltage amplitude in the input amplifier, implies a decrease in the $\mathrm{M}_{3}$ gate voltage (this keeps the branch current constant), meaning a decrease in the $\mathrm{M}_{4}$ 's gate voltage (after filtering), thus decreasing the transistor $\mathrm{M}_{4}$ current itself. When this current reaches a point that cancels with the transistor $\mathrm{M}_{5}$ mirror current, then the output capacitance starts to discharge and the output voltage goes to high.

\section{B. Transmitter}

The ASK modulated signal is generated by means of a switched power amplifier. The power amplifier has a cascade of five inverters, in order to drive the ASK output signal to the input of the power amplifier. The Fig. 3 shows the schematic of the power amplifier, as well as, the whole transmitter. The network $L_{1} C_{1}$ is tuned to the carrier frequency, while the network $L_{2} C_{2}$ reduces the emissions outside of the $2.4 \mathrm{GHz}$ band.

\section{Frequency Synthesizer}

As depicted in Fig. 4(a), the PLL has a reference generator circuit with a crystal-based oscillator at $20 \mathrm{MHz}$, followed by a phase-frequency difference circuit (PFD) without dead zone, a current steering charge pump (CP), and a third-order passive filter. The passive section output is connected to the VCO that generates the desired frequency of $2.4 \mathrm{GHz}$. This frequency must be divided by 120 and connected to the PFD again, closing the loop.

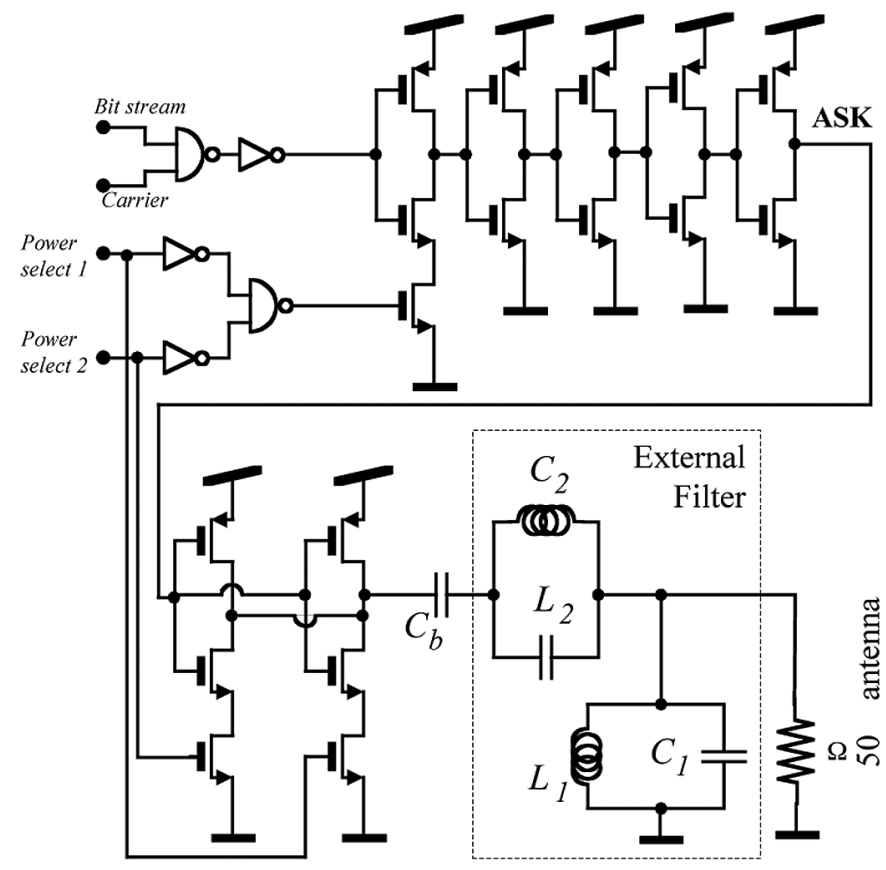

Fig. 3. The schematic of the transmitter.

In real PFDs, there is an offset around the zero phase difference, and a gain inversion region takes place for phase differences higher than $2 \pi-\Delta$ rad. In this gain inversion region, the PFD outputs the wrong control signals increasing the phase and frequency differences between the inputs, and the lock time takes a sudden turn for the worse [5]. The implemented PFD has a linear gain in the range $[-\pi,+\pi]$, and a large constant gain in the range $[-2 \pi,-\pi]$ and $[+\pi,+2 \pi]$ [6]. This type of PFDs makes PLLs faster, compared with those using conventional PFDs.

The charge pump (CP) is of current steering type. This circuit avoids the conventional problem in CPs, which limits the opening and closing of current sources, in fact, in spite of being switched, the current is routing from the load to an alternative path, and from that path to the load.

A current starved ring oscillator was used as voltage controlled oscillator (VCO). Ring oscillators have more phase noise than LC oscillators. For overcoming this limitation, the bandwidth of the PLL must be high enough to "clean-up" the output spectrum around $2.4 \mathrm{GHz}$. A third-order passive filter, composed by a second-order section $\left(C_{1}, C_{2}\right.$, and $\left.R_{2}\right)$ and a firstorder section $\left(C_{3}\right.$ and $\left.R_{3}\right)$, providing an additional pole it is used. The first-order filter reduces spurs caused by the multiples of reference frequency, whose consequence is the increasing of the phase noise at the output. The stability is guaranteed by putting this last pole five times above the PLL bandwidth and below the reference. A bandwidth of approximately two times the difference between the maximum and minimum frequencies generated by the VCO was used. The stability in the loop is obtained with a phase margin of $\pi / 4 \mathrm{rad}$.

The division by 120 in the feedback path is done with a cascade constituted by $1 / 2$ divider implemented with a true-singlephase-clock (TSPC) logic [7], one divider by 30 , followed by a toggle flip-flop to ensure a duty-cycle of 50\% at the PFD input. 


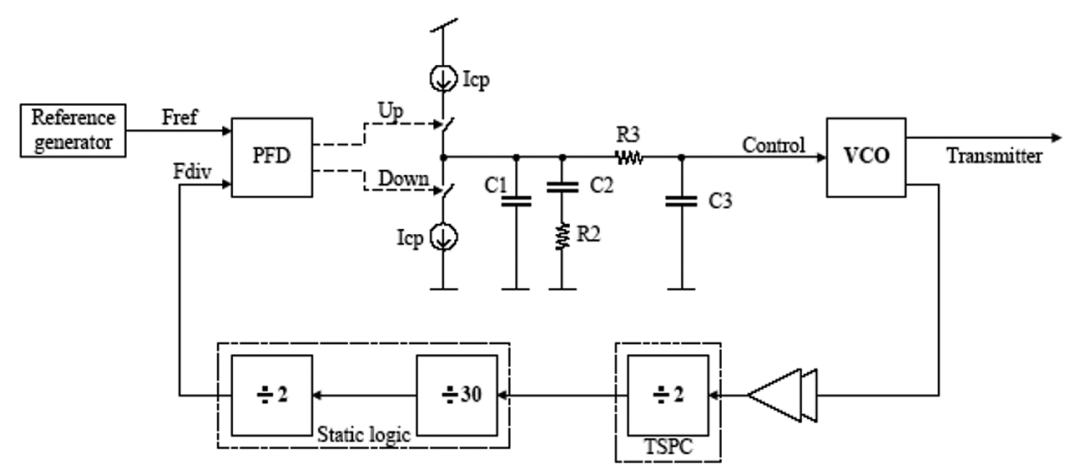

(a)

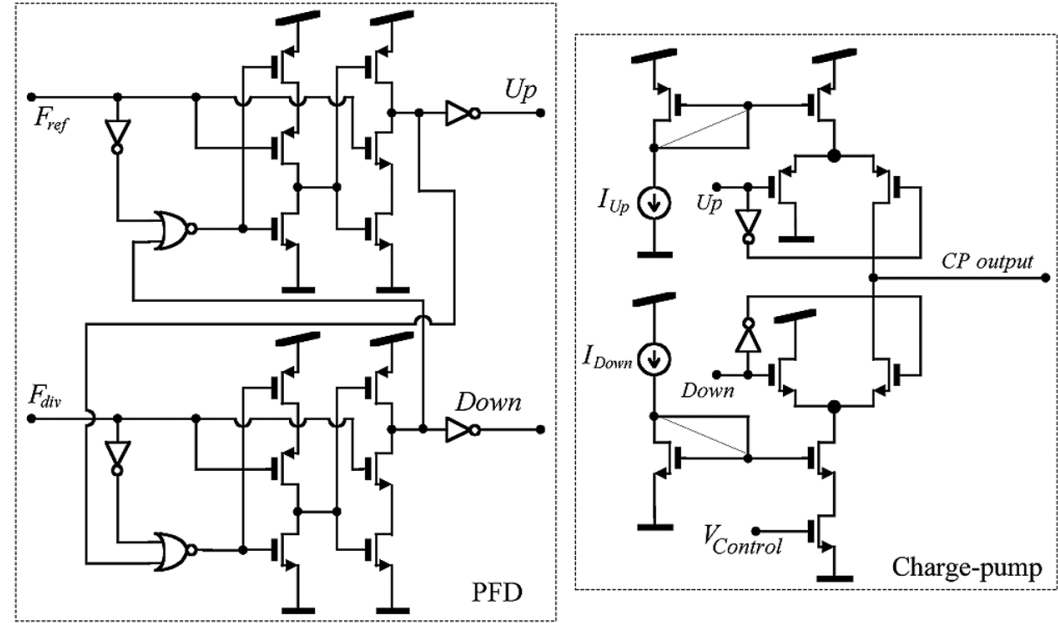

(b)

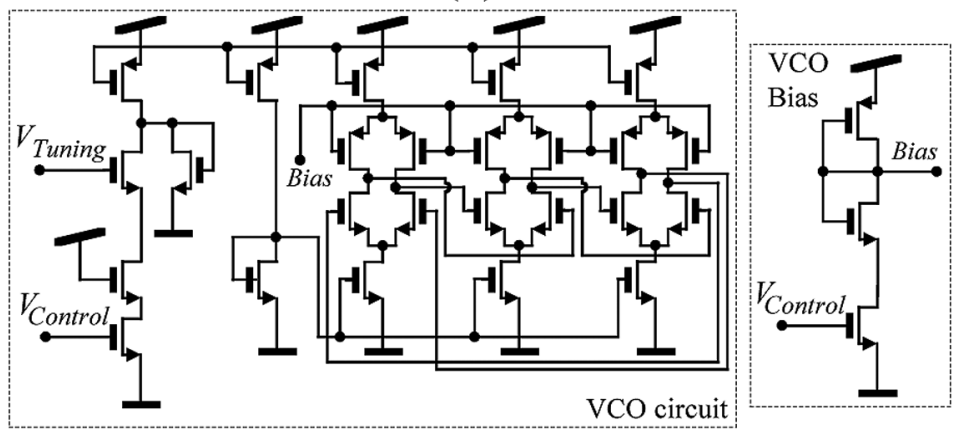

(c)

Fig. 4. (a) The PLL structure, (b) the schematic of the PFD-CP, and (c) the schematic of the VCO.

The TSPC logic was used to overcome the impossibility to implement the first toggle flip-flop with static logic in this technology. It is required a rail-to-rail input to work properly. The ratio of 30 was achieved with the use of simple frequency dividers by $2 / 3$ with modulus control.

\section{Antenna Switch}

The receiver and transmitter subsystems are connected to the antenna by means of a digitally controlled antenna switch. The isolation between nonconnected ports must be high, maintaining low the losses between connected ports. For a compact RF frontend, the integration of the antenna-switch must in the same die of the transceiver [8].

\section{ElECTRODE CONCEPT}

One of the keys to recording good EEG signals is the type of electrodes used. Electrodes that make the best contact with a subject's scalp and contain materials that most readily conduct EEG signals (low impedance), provide the best EEG recordings. Some of the types of electrodes available include the following.

1) Reusable disks. These electrodes can be placed close to the scalp, even in a region with hair because they are small. A small amount of conducting gel needs to be used under each disk. The electrodes are held in place by a washable elastic head band. Disks made of titanium, silver, and gold are available. They can be cleaned, for example, with soap and water. The cost of each disk and lead is dependent on the type of metal used as a conductor, the gauge of wire 
used as a lead, and the type of insulation on the wire lead. Since these electrodes and leads can be used for years, their expense is low.

2) EEG caps with disks. Different styles of caps are available with different numbers and types of electrodes. Some caps are available for use with replaceable disks and leads. Gel is injected under each disk through a hole in the back of the disk. Since the disks on a region of the scalp covered with hair cannot be placed as close to the scalp as individual disc electrodes, a greater amount of conducting gel needs to be injected under each. After its use, more time is required to clean the cap and its electrodes, as well as the hair of the subject. Depending on the style and longevity of the cap and the electrodes, their expense can be moderate to high.

3) Adhesive gel electrodes. These are the same disposable $\mathrm{Ag} / \mathrm{AgCl}$ electrodes used to record ECGs and EMGs, and they can be used with the same snap leads used for recording those signals. These electrodes are an inexpensive solution for recording from regions of the scalp without hair. They cannot be placed close to the scalp in regions with hair, since the adhesive pad around the electrode would attach to hair and not the scalp. When purchased in bulk, their expense is very low.

Beyond its electrical properties, another and not less important requirement for good electrodes is the issue related to the biocompatibility. The best definition of biocompatibility is the ability of a material to perform with an appropriate host response in a specific application, thus EEG electrodes must match this requirement. Following, it is shown a comparison of used electrodes, e.g., the silver/silver chloride $(\mathrm{Ag} / \mathrm{AgCl})$ electrodes, the sputtered titanium nitride (TiN) electrodes and the sputtered iridium oxide $\left(\mathrm{IrO}_{2}\right)$ electrodes. Polarizable electrodes such as stainless steel and platinum are not suitable for the application described on this paper, due to its noneffectiveness on the recording of EEG slow-potentials [9].

\section{A. Silver/Silver Chloride $(\mathrm{Ag} / \mathrm{AgCl})$ Electrodes}

Commercial sintered $\mathrm{Ag} / \mathrm{AgCl}$ ring electrodes for guaranteeing low constant transition resistance were used in the measurements. This type of electrode is usually used in EEG sessions with patients.

\section{B. Sputtered Titanium Nitride (TiN) Electrodes}

TiN was deposited by means of DC magnetron sputter deposition from a Ti target in an $\mathrm{Ar} / \mathrm{N}_{2}$ plasma. A Nordiko NS 2550 sputtering equipment was used for TiN deposition and the sputtering chamber was evacuated to at least $4 \times 10-6$ mbar by means of a cryogenic pump. A previous study of the nitrogen gas flow (between 0.6 and $2.2 \mathrm{sccm}$ ) showed that for the same pumping speed $(270 \mathrm{l} / \mathrm{s})$ and a power of $500 \mathrm{~W}$ the lowest resistance is achieved with $0.8 \mathrm{sccm} \mathrm{N} \mathrm{N}_{2}\left(440 \times 10^{-6} \Omega . \mathrm{cm}\right.$ at films with a thickness of $230 \mathrm{~nm}$ ).

\section{Sputtered Iridium Oxide $\left(\mathrm{IrO}_{2}\right)$ Electrodes}

Also, $\mathrm{IrO}_{2}$ was deposited by means of DC magnetron sputter deposition from a target in an $\mathrm{Ar} / \mathrm{O}_{2}$ plasma, prior to which a $\mathrm{Ti}$ adhesion layer (with a thickness of $50 \mathrm{~nm}$ ) was deposited on the substrate. The oxygen gas flow was fixed at $1.85 \mathrm{sccm}$ according to the procedure described in [10]. The $\mathrm{IrO}_{2}$ resistance

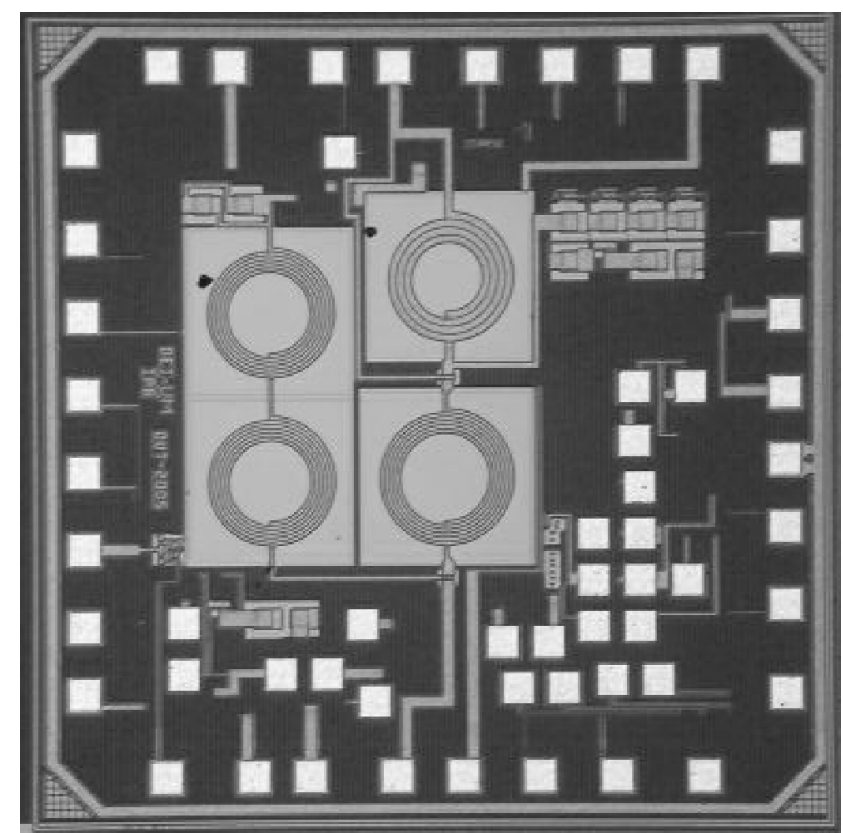

Fig. 5. Photography of the fabricated RF transceiver.

in a 270 -nm-thick film was $349 \times 10^{-6} \Omega . \mathrm{cm}$. The film thicknesses were determined via liftoff process with a Tencor $\mathrm{Pa}-10$ profilometer. The thin film resistance was measured in a classic four-point probe system.

\section{Electrodes Impedance Comparison}

Electrode impedance reflects the electrode's capability to transfer signals at a given frequency. For the desired frequencies (up to $30 \mathrm{~Hz}$ ), the standard $\mathrm{Ag} / \mathrm{AgCl}$ and $\mathrm{TiN}$ electrodes have typical contact resistances less than: $1-6 \mathrm{k} \Omega, 29-80 \mathrm{k} \Omega$. The electrodes using traditional materials, such as the stainless steel, platinum, and gold, the impedances are as following: for the stainless steel and platinum, the impedance responses go almost immediately out of a maximum given scale of $120 \mathrm{k} \Omega$, because of rapid polarization. The commercial gold electrodes has a typical impedance of 50-92 k . Gold electrodes presents very high values, compared with those found in the $\mathrm{Ag} / \mathrm{AgCl}$ and TiN electrodes, which are not higher than 1-6 and 29-80 k , respectively [11].

\section{MEASUREMENT AND ANALYSIS}

\section{A. RF Transceiver}

Fig. 5 shows the photograph of the RF CMOS transceiver die, which occupies an area of $1.5 \times 1.5 \mathrm{~mm}^{2}$, but the final structure can be optimized for including processing electronics for the acquired neural signals.

The experimental tests made to the transceiver showed a total power consumption of $6.3 \mathrm{~mW}$ for the receiver $(4 \mathrm{~mW}$ for the LNA, and $2.3 \mathrm{~mW}$ for the postamplifier + envelope detector). The transmitter delivers a maximum output power of $1.28 \mathrm{~mW}$ (very close to the specified $0 \mathrm{dBm}$ ) with a power consumption of $11.2 \mathrm{~mW}$.

The LNA has a gain of $15.1 \mathrm{~dB}$, a NF of $1.076 \mathrm{~dB}$ (noise factor $F=1.28$ ) and a $1 \mathrm{~dB}$ compression point of $-12.4 \mathrm{dBm}$. The LNA has also the stabilization factor $K=1.4$ (greater than 


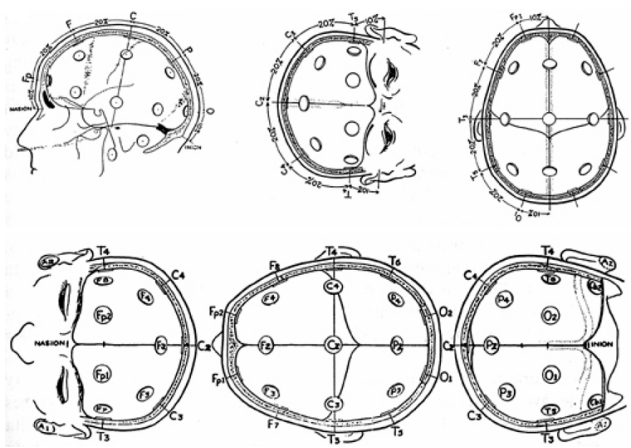

Fig. 6. The 10-20 electrode system is recommended by the International Federation of EEG Societies. The left bottom image shows the position FP2 used in the measurements.

the unity), that makes this amplifier unconditionally stable. The $\mathrm{CP}$ has Up and Down currents of $I_{\mathrm{Up}}=173 \mu \mathrm{A}$ and $I_{\text {Down }}=$ $178 \mu \mathrm{A}$, respectively, and with a detector constant gain $K_{\phi}=$ $175 \mu \mathrm{A} / 2 \pi \mathrm{rad}$. The used VCO has the advantage to control the full range $[0,1.8 \mathrm{~V}]$, providing a frequency range of [2.016, $2.757 \mathrm{GHz}$, with a tuning constant $K_{\mathrm{VCO}}=876.6 \mathrm{MHz} / \mathrm{V}$, calculated in the linear working range.

The antenna switch provides a minimum port isolation of $41.5 \mathrm{~dB}$ and a maximum insertion loss of $1.3 \mathrm{~dB}$, overcoming reference values [8]. It was selected as a commercial antenna measuring $6.1 \times 3.1 \times 1 \mathrm{~mm}$ and weighting $0.05 \mathrm{~g}$. This antenna has a maximum return loss of $2.5 \mathrm{~dB}$, a bandwidth of $40 \mathrm{MHz}$, an efficiency of $55 \%$, and a nominal impedance of $50 \Omega$ in the $[2.4,2.5 \mathrm{GHz}]$ frequency range.

\section{B. EEG Electrodes}

The amplitude of the EEG is about $70 \mu \mathrm{V}$ when measured on the scalp. The bandwidth of this signal is from under $1 \mathrm{~Hz}$ to about $50 \mathrm{~Hz}$. The data-acquisition system used in the experiments is composed of an amplifier with 40 channels, connected to analog-to-digital converters of 22-bits (sampling frequency at $2000 \mathrm{~Hz}$ ), and a braincap with large filling holes and flat clip-on adapters making skin preparation and gel application simpler, improving preparation time. The amplifier is connected to a PC (via USB) that runs the recording software. The recording electrode was applied in the frontopolar area (in position FP2) in a standard configuration 10-20 system used in EEG clinical diagnostics and the other electrode of the pair was the reference (see Fig. 6).

During the measurements, the patients were in contemplation of a picture for trying to avoid the frequently blinking of the eyes during $3 \mathrm{~min}$. The study contemplated the extraction of the power of the signal in FP2 versus the frequency, using the fast Fourier transform (FFT) in the range of interest, $0.5-30 \mathrm{~Hz}$, for EEG (analyzing the Delta $0.5-3 \mathrm{~Hz}$, Theta 3-7 Hz, Alpha 7-13 Hz, and Beta 13-30 Hz waves). Figs. 7-9 show the FFT response of the sputtered TiN electrodes, standard sintered $\mathrm{Ag} / \mathrm{AgCl}$ ring electrodes and sputtered $\mathrm{IrO}_{2}$ electrodes, respectively.

The FFT response was obtained in terms of power of the signal $\left(\mu \mathrm{V}^{2}\right)$ versus the frequency. The amplitude of the signal in average is higher for the $\mathrm{IrO}_{2}$ electrodes (high-amplitude

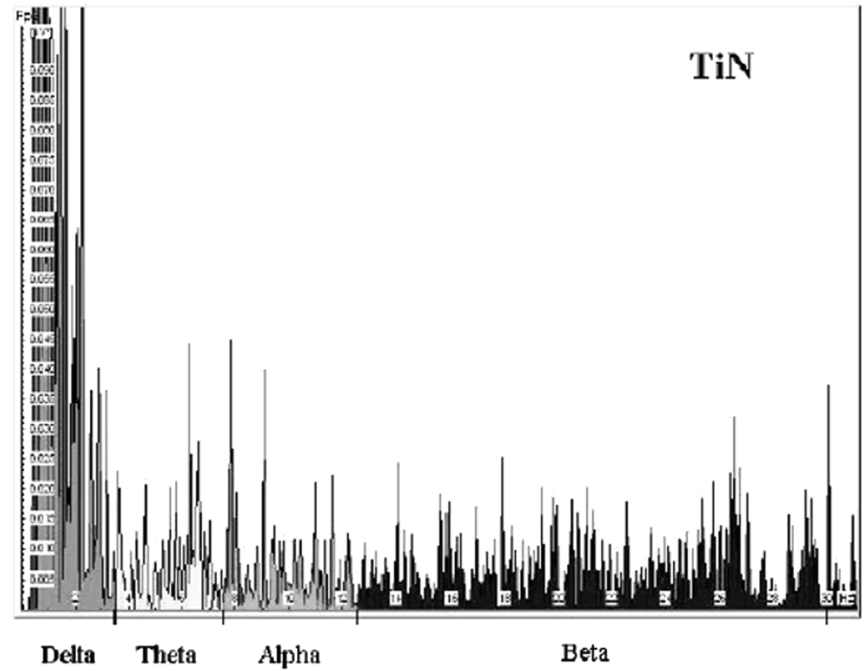

Fig. 7. The FFT response of the sputtered TiN electrodes in terms of power $\left(\mu \mathrm{V}^{2}\right)$ versus frequency.

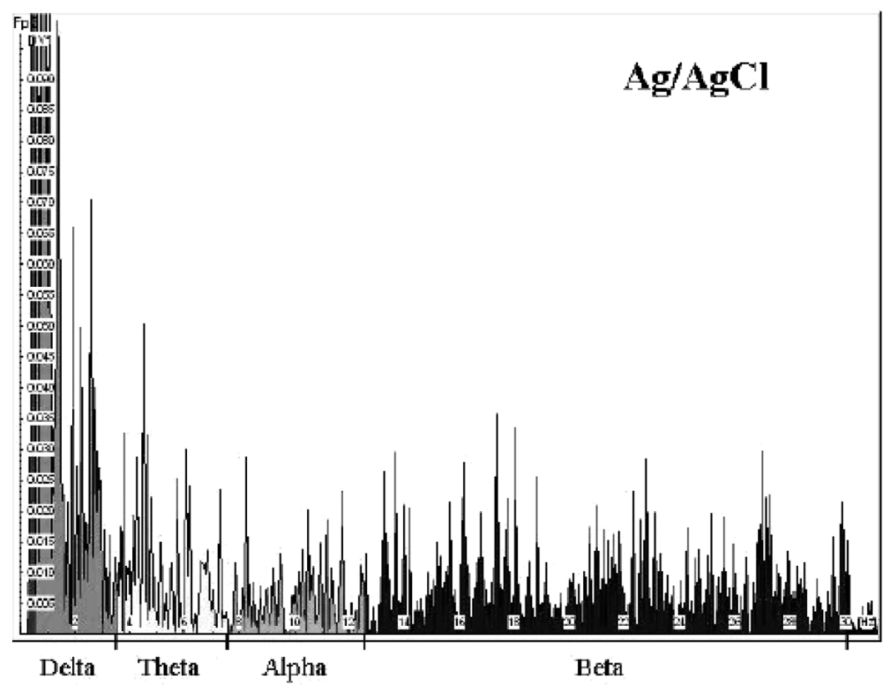

Fig. 8. The FFT response of the standard sintered $\mathrm{Ag} / \mathrm{AgCl}$ ring electrodes in terms of power $\left(\mu \mathrm{V}^{2}\right)$ versus frequency.

signals in subdelta). Also, they have an excellent response in Theta and Beta waves compared with the standard sintered $\mathrm{Ag} / \mathrm{AgCl}$ ring electrodes. The sputtered TiN electrodes shows an excellent amplitude signal in Alpha waves but they show the lowest amplitude of the signal in average compared with the standard sintered $\mathrm{Ag} / \mathrm{AgCl}$ ring electrodes and the sputtered $\mathrm{IrO}_{2}$ electrodes. In [12], sputtered TiN thin films deposited with a pumping speed of $9 \mathrm{l} / \mathrm{s}$ and a power of $2.2 \mathrm{~kW}$, and nitrogen gas flow of $3.4 \mathrm{sccm}$ showed a resistance in the range of $27 \times 10^{-6} \Omega \cdot \mathrm{cm}$ to $33 \times 10^{-6} \Omega \cdot \mathrm{cm}$. Comparing with the sputtered TiN films resistance fabricated in this work, we believe that their performance as EEG electrodes will be improved.

\section{WIRELESS EEG ModulE}

The standard wireless EEG solutions use a braincap with wires running from the electrodes position to a bulky central 


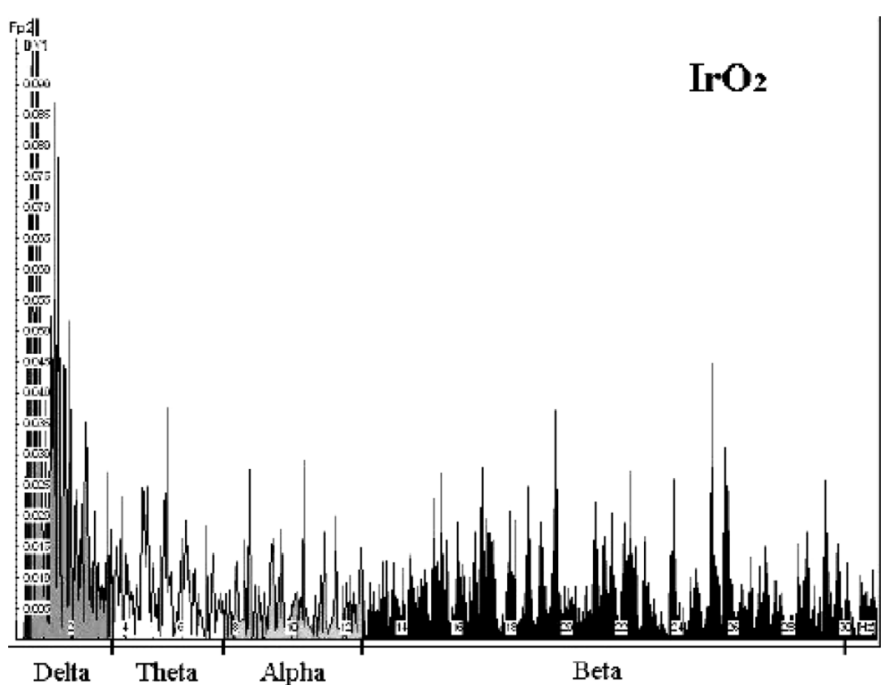

Fig. 9. The FFT response of the fabricated sputtered $\mathrm{IrO}_{2}$ electrodes in terms of power $\left(\mu \mathrm{V}^{2}\right)$ versus frequency.

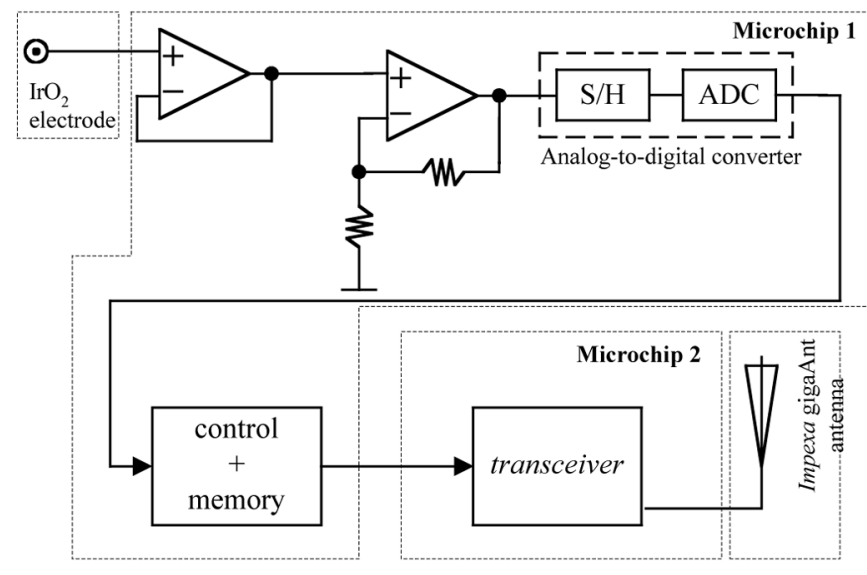

Fig. 10. Wireless EEG module. Note that the neutral electrode, which is connected to the grounds of the module it is not shown.

unity (amplification, signal filtering and analog-to-digital conversion, RF transceiver, and antenna) [1]. A more interesting solution is to use compact wireless EEG modules, where the electronics, the antenna, and each electrode are mounted together. The power supply for these modules is obtained locally from a coin-sized battery placed in the braincap.

Bipolar or unipolar electrodes can be used in the EEG measurement. In the first method, the potential difference between a pair of electrodes is measured. In the second method, the potential of each electrode is compared, either to a neutral electrode or to the average of all electrodes. Fig. 10 shows the full schematic of the wireless EEG module, where it can be seen the electrode connected to an amplifier, followed by an A-to-D converter. In order to meet the EEG specifications, the amplifier was designed to have enough gain, to amplify signals with amplitudes of only $70 \mu \mathrm{V}$. The analog-to-digital converter (ADC) was designed to have a resolution of 22 bits and a minimum sampling frequency of $2000 \mathrm{~Hz}$. The electronics comprising the control logic and the memory was designed together with the amplifier and ADC in the same microchip.
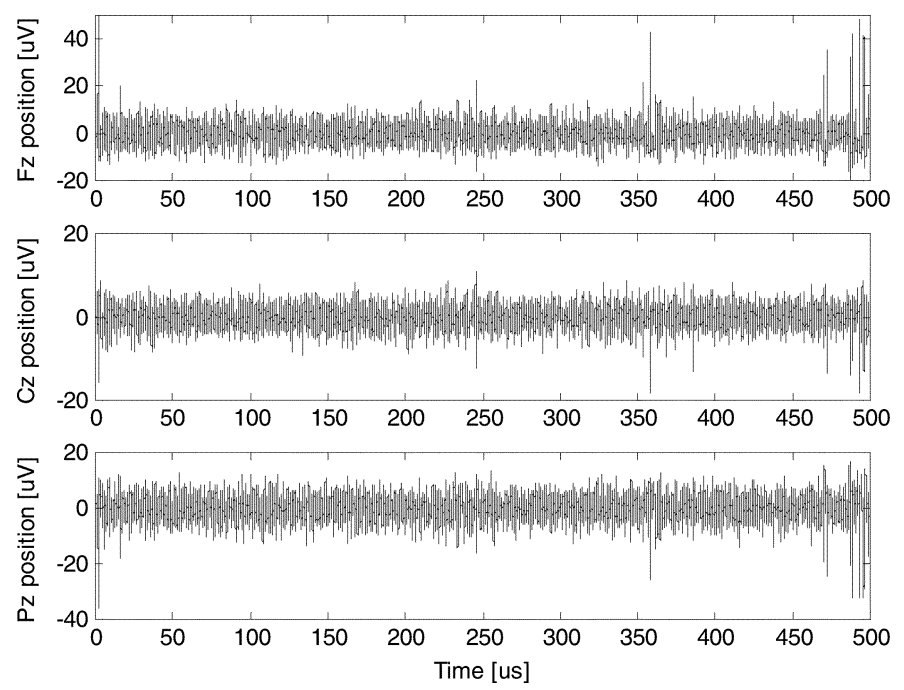

Fig. 11. Reconstructed EEG signals, simultaneously acquired in the $\mathrm{Fz}, \mathrm{Cz}$, and $\mathrm{Pz}$ positions.

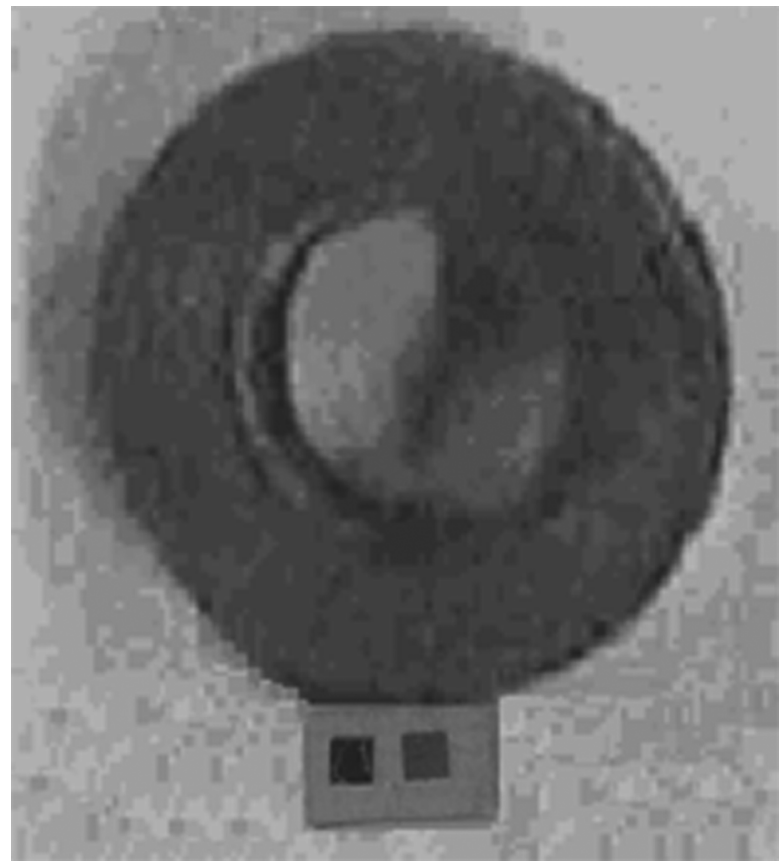

Fig. 12. A module photograph, where it is shown the sputtered $\mathrm{IrO}_{2}$ electrode mounted together with the electronics (the microchip on the left), the RF transceiver (the microchip on the right) and a planar antenna.

In Fig. 11, it can be seen, three simultaneous acquired (reconstructed) signals from three of the proposed wireless EEG modules. These signals were obtained during a period of $500 \mu \mathrm{s}$, from $\mathrm{Fz}, \mathrm{Cz}$, and $\mathrm{Pz}$ positions. The dynamic variation of the three EEG signals didn't exceed $70 \mu \mathrm{V}$.

The modules must offer the plug-and-play feature, in order to mount distributed networks in the patient's head. Moreover, as the EEG data is periodically acquired in all the modules, thus the latencies of data transmissions are not allowed. The proposed EEG modules uses a communication protocol that overcomes these problems [13]. This protocol combines the distributed and coordination modes, e.g., when a new module is putted in the head of patient, a contention-based time interval is used to make 
the registration request in the network. A contentionless time interval, constituted by timeslots, is granted to the new EEG module if the registration is successful completed on the network. The maximum number of simultaneous modules is limited to the number of time-slots in the contention-free interval.

The Fig. 12 is a photograph of the full wireless EEG module, where it is shown the sputtered $\mathrm{IrO}_{2}$ electrode mounted together with the processing and control electronics (is the microchip located above), the RF transceiver (is the microchip located below), and an associated antenna. The whole electronics and the associated antenna are mounted in the back of the electrode package.

This solution fits the medical doctor requirements for an easy placement and removal of the electrodes in the braincap. Moreover, with this solution it is very easy to populate electrodes in different positions or takeoff. In many medical diagnostics, the patients are monitored only with a low number of electrodes (e.g., 2-5 electrodes), making possible to mount an EEG wireless-electrodes network with these plug-and-play modules.

\section{CONCLUSION}

A low-power/low-voltage RF transceiver for a wireless EEG single-electrode module was fabricated in a UMC RF CMOS $0.18 \mu \mathrm{m}$ process. The transceiver consumes $6.3 \mathrm{~mW}$ in the receive mode and delivers $0 \mathrm{dBm}$ with a power consumption of $11.2 \mathrm{~mW}$ in the transmitting mode. These characteristics fulfill the requirements for short-range communications for using the $2.4 \mathrm{GHz}$ ISM band.

Also presented was the electrode concept, showing the fabrication process of three different EEG electrodes with a special focus in the sputtered $\mathrm{IrO}_{2}$ electrodes, due to its very useful dry usage capability in EEG application with our module. The experimental results show a better performance of the sputtered $\mathrm{IrO}_{2}$ electrodes (high-amplitude signal average) compared with the standard sintered $\mathrm{Ag} / \mathrm{AgCl}$ ring electrodes and sputtered TiN electrodes. Sputtered $\mathrm{IrO}_{2}$ electrodes have shown good performance as stimulating electrodes (high charge delivery capacity and low, constant impedance over the entire frequency range for neural stimulation) [14], [15], and with these experiments they promise to be a good solution as recording electrodes in noninvasive EEG. In all experiments electrolytic gels were used. This results in long application times (up to several minutes per electrode) and long stabilization times (diffusion of the electrolytic gel into the skin) [16]. The results promises a new opportunity for fabricating a dry sputtered $\mathrm{IrO}_{2}$ electrodes that can penetrate the outer skin layer (5-10 $\mu \mathrm{m}$ thick), called Stratum Corneum (for avoiding its high-impedance characteristics) without the use of the electrolytic gel. Moreover, sputtered $\mathrm{IrO}_{2}$ electrodes do not present the known problems that $\mathrm{Ag} / \mathrm{AgCl}$ electrodes showed in contact with biological tissue; the silver chloride on the surface dissolves and causes inflammations due to its toxicity [12].

Also presented was a plug-and-play EEG module composed by the fabricated RF transceiver, a second microchip comprising processing and control electronics, an associated antenna, and a sputtered $\mathrm{IrO}_{2}$ EEG electrode. The main goal is improving the EEG medical diagnostics and therapy by using devices, which reduces healthcare costs and facilitates the diagnostic, while preserving at the same time the mobility and lifestyle of patients.

\section{REFERENCES}

[1] IMEC press releases, "Ambulatory EEG," Human ++ EU Project, 2003, pp. 1-2.

[2] P. Choi et al., "An experimental coin-sized radio for extremely lowpower WPAN (IEEE 802.15.4) applications at $2.4 \mathrm{GHz}$," IEEE J. SolidState Circuits, vol. 38, no. 12, pp. 2258-2268, Dec. 2003.

[3] D. Shaeffer and T. Lee, "A 1.5-V, 1.5-GHz CMOS low-noise amplifier," IEEE J. Solid-State Circuits, vol. 39, no. 4, pp. 569-576, Apr. 2004.

[4] F. Alimenti et al., "Modeling and characterization of the bonding-wire interconnection," IEEE Trans. Microwave Tech., vol. 49, no. 1, pp. $142-150$, Jan. 2001.

[5] K. Lee, B. Park, H. Lee, and M. Yoh, "Phase-frequency detectors for fast frequency acquisition in zero-dead-zone CPPLLs for mobile communication systems," in Proc. 29th Eur. Solid-State Circuits Conf., Estoril, Portugal, Sep. 2003, pp. 16-18.

[6] B. Kim and L. Kim, "A 250-MHz-2-GHz wide-range delay-locked loop," IEEE J. Solid-State Circuits, vol. 40, no. 6, pp. 1310-1321, Jun. 2005.

[7] S. Pellerano et al., "A $13.5 \mathrm{~mW} 5-\mathrm{GHz}$ frequency synthesizer with dynamic logic frequency divider," IEEE J. Solid-State Circuits, vol. 39, no. 2, pp. 378-383, Feb. 2004.

[8] M. Ugajin et al., "A 1-V CMOS SOI Bluetooth RF transceiver using LC-tuned and transistor-current-source folded circuits," IEEE J. SolidState Circuits, vol. 39, no. 4, pp. 745-759, May 1997.

[9] A. Ikeda et al., "Reappraisal of the effect of electrode property on recording slow potentials," J. Electroenephalography and Clinical Neurophysiology, vol. 107, no. 1, pp. 59-63, Jul. 1998.

[10] B. Wessling, W. Mokwa, and U. Schnakenberg, "RF-sputtering of iridium oxide to be used as stimulation material in functional medical implants," J. Micromech. Microeng., vol. 16, pp. 142-148, 2007.

[11] P. Tallgren et al., "Evaluation of commercially available electrodes and gels for recording of slow EEG potentials," Clinical Neurophysiology, vol. 116, no. 4, pp. 799-806, Apr. 2005.

[12] W. Heuvelman et al., "TiN reactive sputter deposition studied as a function of the pumping speed," in Thin Solid Films, No. 332. New York: Elsevier Science, 1998, pp. 335-339.

[13] J. Afonso et al., "MAC protocol for low-power real-time wireless sensing and actuation," in Proc. 13th IEEE Int. Conf. Electronics, Circuits, Syst,, , Nice, France, pp. 1248-1251.

[14] E. Slavcheva et al., "Sputtered iridium oxide films as charge injection material for functional electrostimulation," J. Electrochemical Society, vol. 151, no. 7, pp. 226-237, May 2004.

[15] W. Mokwa, "MEMS technologies for epiretinal stimulation of the retina," J. Micromech. Microeng., vol. 14, pp. 12-16, Aug. 2004, IOP.

[16] P. Griss et al., "Micromachined electrodes for biopotential measurements," J. Micromech. Syst., vol. 10, no. 1, pp. 10-16, Mar. 2001.

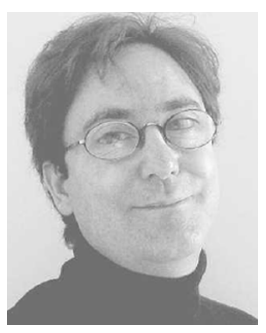

João Paulo Carmo (S'04) graduated in 1993 and received the M.Sc. degree both in electrical engineering and computers from the University of Porto, Porto, Portugal, in 2002 and the Ph.D. degree in industrial electronics from the University of Minho, Guimarães, Portugal, in 2007.

Since 1999, he has been a Lecturer at the Polytechnic Institute of Bragança, Bragança, Portugal. He is also a Researcher at the Algoritmi Center, University of Minho. He is currently involved in the research on RF applications and wireless microsystems.

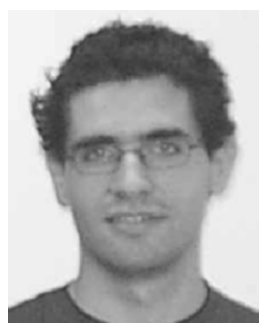

Nuno Sérgio Dias (S'07) graduated with a degree in industrial electronics and computers from the University of Minho, Guimaães, Portugal, in 2004. He is currently working towards the Ph.D. degree at the University of Minho and his thesis deals with brain computer interface systems. 


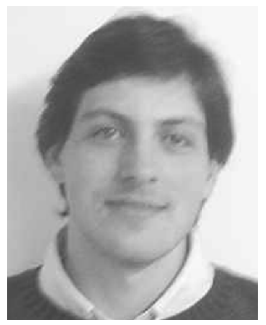

Helder Raul Silva graduated with a degree in industrial electronics and computers from the University of Minho, Guimarães, Portugal, in 2006. He is currently working towards the M.Sc. degree in industrial electronics from the University of Minho and is working as a Research Assistant in biomedical wearable systems.

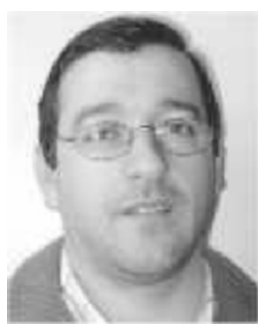

Paulo Mateus Mendes (M'05) graduated in 1995, and received the M.Sc. degree in electrical engineering-electronics and telecommunications in 1999, both from the University of Coimbra, Coimbra, Portugal, and the Ph.D. degree in industrial electronics-electronics and instrumentation from the University of Minho, Guimarães, Portugal, in 2005.

Since 2006, he has been an Assistant Professor at the University of Minho, and a Researcher at the Algoritmi Center. He has been involved in several projects related to project, fabrication, and characterization of microantennas for wireless microsystems.

Dr. Mendes is a member of the European Microwave Association, of the IEEE Antennas and Propagation Society, and of the IEEE Engineering in Medicine and Biology Society.

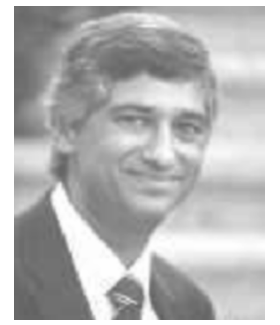

Carlos Couto (SM'03) graduated with a degree in electrical engineering from the University of Lourenço Marques, Mozambique, in 1972. He received the M.Sc. and Ph.D. degrees from the University of Manchester Institute of Science and Technology (UMIST), Manchester, U.K., both in power electronics, in 1979 and 1981, respectively.

In 1976, he joined the University of Minho, Guimarães, Portugal, where since 1995, he has been a Full Professor with the Department of Industrial Electronics. His research interests are microsystems, instrumentation, and power electronics.

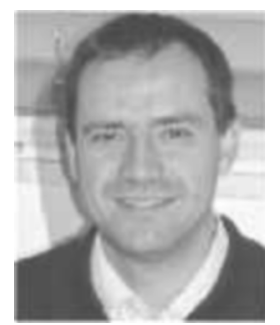

José Higino Correia (S'96-M'00) graduated with a degree in physical engineering from the University of Coimbra, Coimbra, Portugal, in 1990. He received the $\mathrm{Ph} . \mathrm{D}$. degree from the Laboratory for Electronic Instrumentation, Delft University of Technology, Delft, The Netherlands, in 1999, working in the field of microsystems for optical spectral analysis.

Presently, he is an Associate Professor with the Department of Industrial Electronics, University of Minho, Guimarães, Portugal. He was the General Chairman of Eurosensors 2003, Guimarães, Portugal. His professional interests are in micromachining and microfabrication technology for mixed-mode systems, solid-state integrated sensors, microactuators, and microsystems. 